\title{
Insignificant change in Antarctic snowmelt volume since 1979
}

\author{
P. Kuipers Munneke, ${ }^{1}$ G. Picard ${ }^{2}$ M. R. van den Broeke, ${ }^{1}$ J. T. M. Lenaerts, ${ }^{1}$ \\ and E. van Meijgaard ${ }^{3}$ \\ Received 31 October 2011; revised 6 December 2011; accepted 10 December 2011; published 13 January 2012.
}

[1] Surface snowmelt is widespread in coastal Antarctica. Satellite-based microwave sensors have been observing melt area and duration for over three decades. However, these observations do not reveal the total volume of meltwater produced on the ice sheet. Here we present an Antarctic melt volume climatology for the period 1979-2010, obtained using a regional climate model equipped with realistic snow physics. We find that mean continent-wide meltwater volume (1979-2010) amounts to $89 \mathrm{Gt} \mathrm{y}^{-1}$ with large interannual variability $\left(\sigma=41 \mathrm{Gt}^{-1}\right)$. Of this amount, $57 \mathrm{Gt} \mathrm{y}^{-1}(64 \%)$ is produced on the floating ice shelves extending from the grounded ice sheet, and $71 \mathrm{Gt} \mathrm{y}^{-1}$ in West-Antarctica, including the Antarctic Peninsula. We find no statistically significant trend in either continentwide or regional meltwater volume for the 31-year period 1979-2010. Citation: Kuipers Munneke, P., G. Picard, M. R. van den Broeke, J. T. M. Lenaerts, and E. van Meijgaard (2012), Insignificant change in Antarctic snowmelt volume since 1979, Geophys. Res. Lett., 39, L01501, doi:10.1029/2011GL050207.

\section{Introduction}

[2] While almost all meltwater produced in Antarctica refreezes in the snow and firn and therefore does not contribute directly to sea-level rise, knowing its total volume is important for at least two reasons. First of all, the role of meltwater-induced weakening of ice shelves prior to their breakup in recent times [Scambos et al., 2000] can be assessed quantitatively when it is known how much meltwater would be available for these weakening processes. Second, the interpretation of elevation changes measured by altimeters onboard satellites is hampered by lacking knowledge of variability in firn density. Firn densification is highly sensitive to melt [Helsen et al., 2008] so any model correcting elevation changes in order to obtain mass changes requires accurate melt fluxes as input.

[3] Satellite-based microwave radiometers can detect liquid water since microwave emissivity of wet snow is much higher than that of dry snow [Zwally and Fiegles, 1994; Liu et al., 2006; Tedesco et al., 2007; Picard et al., 2007]. These brightness temperature observations yield approximate values for melt duration, melt area, and the cumulative melting surface (CMS, also called melt index by [Zwally and Fiegles, 1994; Tedesco et al., 2007; Tedesco, 2009]), being the product of melt duration and area. CMS can act as a useful

\footnotetext{
${ }^{1}$ Institute for Marine and Atmospheric Research, Utrecht University, Utrecht, Netherlands.

${ }^{2}$ Laboratoire de Glaciologie et Géophysique de l'Environnement, CNRS/UJF, St Martin d'Hères, France.

${ }^{3}$ Royal Netherlands Meteorological Institute, De Bilt, Netherlands.

Copyright 2012 by the American Geophysical Union. 0094-8276/12/2011GL050207
}

remotely-sensed climatic indicator. The most significant limitation to satellite microwave sensors is that they can only detect if a surface is melting, not the melt rate [Van den Broeke et al., 2010]. For that, a snow model would be required, that uses net surface energy fluxes from an atmospheric model as the source for heating and melting of the snow. Here, we present a time series of meltwater volume using the regional climate model RACMO2 (Regional Atmospheric Circulation Model 2) that has been two-way coupled to a multi-layer snow model that takes into account melting, percolation, and refreezing in the snow [Ettema et al., 2010]. The atmospheric part of RACMO2 provides precipitation fields, as well as temperature, wind, humidity, and radiation fluxes to compute the surface energy balance. Any excess of surface energy heats the snowpack, and melts it when the melting point is reached. In the surface energy budget, the absorption of solar radiation is the dominant and a particularly sensitive component, governed by changes in surface albedo. A snow microphysical parameterization of albedo was implemented in RACMO2 [Kuipers Munneke et al., 2011] that allows for a realistic simulation of absorbed solar radiation. This is of key importance, since absorption of solar radiation and snowmelt engage in a positive melt-albedo feedback where more melt leads to larger snow grains that absorb more radiation, which in its turn allows for more melt.

\section{Antarctic Melt Volume}

[4] The 27-km resolution RACMO2 computational domain, that extends well over the Southern Ocean, was forced at the boundaries by ERA-Interim reanalysis data between 1979 and 2010. The resulting time series of melt integrated over the entire continent, as well as over 6 Antarctic regions, is shown in Figure 1. Years in the figures and in the text refer to the period of 1 April of that year until 31 March of the next year, so that Austral summers do not get split. To compute a clean and unbiased meltwater volume climatology, the area of the ice shelves that disappeared between 1979 and 2010 is excluded from the analysis of the entire period. Mean annual meltwater production is $89 \mathrm{Gt} \mathrm{y}^{-1}$ with large interannual variability $\left(\sigma=41 \mathrm{Gt} \mathrm{y}^{-1}\right)$. Record-high melt volume occurred in 1992/93 (181 Gt $\left.{ }^{-1}\right)$ whereas 2008/09 shows the lowest volume of the record $\left(29 \mathrm{Gt} \mathrm{y}^{-1}\right)$. About $64 \%$ of all meltwater is produced on the ice shelves. Averaged over the entire continent, melt constitutes slightly less than $4 \%$ of the annual Antarctic snowfall (J. T. M. Lenaerts et al., A new high-resolution surface mass balance map of Antarctica (1989-2009) based on regional climate modelling, unpublished manuscript, 2011). For a regional view, we divided the ice sheet into 6 areas following [Zwally and Fiegles, 1994] (Figure 2 and Table 1) and show time series of melt volume for these regions in Figure $1 \mathrm{~b}$. By far most of the melt is produced in the Antarctic Peninsula 


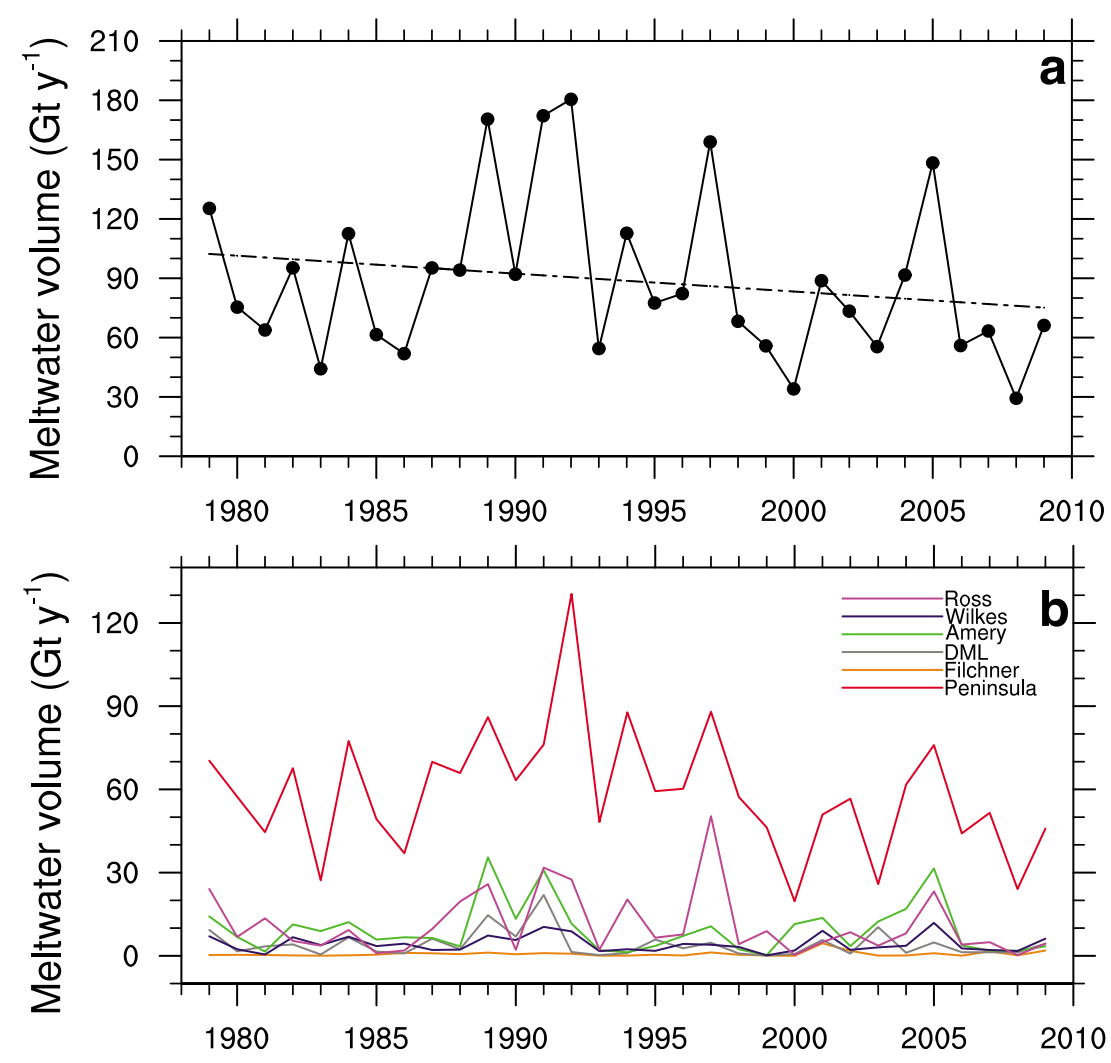

Figure 1. (a) Surface meltwater volume produced annually, integrated over the entire ice sheet plus adjacent ice shelves (in Gt $\mathrm{y}^{-1}$ ). (b) As in Figure 1a but specified for each region defined by the black boxes in Figure 2.

(region 1, $59 \mathrm{Gt}^{-1}$ ), followed by region 6 including the Ross ice shelf and all shelves fringing Marie Byrd Land $(11.1 \mathrm{Gt}$ $\mathrm{y}^{-1}$ ), and the Amery/West/Shackleton ice shelves (region 4, 9.6 $\left.\mathrm{Gt} \mathrm{y}^{-1}\right)$. Average melt rates (1979/80-2009/10) per unit of area are shown in the map in Figure 2, reaching values up to $1000 \mathrm{~mm}$ w.e. $\mathrm{y}^{-1}$ in the Peninsula (most notably in the north), on the Larsen ice shelves in the East, and on the George VI and Wilkins shelves on the Western side of the Peninsula. Other local hotspots include the Abbot ice shelf region (up to $340 \mathrm{~mm}$ w.e. $\mathrm{y}^{-1}$ ), and the West and Shackleton ice shelves (up to $250 \mathrm{~mm}$ w.e. $\mathrm{y}^{-1}$ ). Large parts of coastal East Antarctica exhibit annual mean melt rates of about 10-50 $\mathrm{mm}$ w.e. $\mathrm{y}^{-1}$.

\section{Satellite Validation}

[5] We evaluated the RACMO2 melt climate by calculating a model-CMS (see text S1 in the auxiliary material), so that RACMO2 results can be compared with satellite microwave data. ${ }^{1}$ In fact, we are taking a step back with RACMO2 by just determining if the surface is melting, disregarding the melt volume [see also Fettweis et al., 2011]. Satellite microwave data are provided by SMMR (Scanning Multichannel Microwave Radiometer) before 1 July 1987 and SSM/I (Special Sensor Microwave/Imager) platforms after that. SMMR data are available only every other day, so for any missing day, we have linearly interpolated the brightness temperature using the previous and the next day.

${ }^{1}$ Auxiliary materials are available in the HTML. doi:10.1029/ $2011 \mathrm{GL} 050207$.
The SSM/I satellites have acquisition hours that bias towards the evening and the night, thus tending to underestimate the amount of melt events [Picard and Fily, 2006]. For a fair comparison between RACMO2 and SSM/I, RACMO2 snowmelt was therefore resampled as the mean of the melt at 5.00 and 22.00 local time for each location, which are the times representative of the SSM/I acquisition hours. The SMMR data are acquired approximately noon and midnight, and RACMO2 snowmelt was resampled accordingly for the SMMR era. This satellite-synchronized CMS series compares favorably with satellite observations (Figure 3a), while also capturing the interannual variability. The agreement deteriorates somewhat during the SMMR era (prior to 1987), which is partly due to uncertainty in the satellite data: since SMMR acquires a melt map every two days, the interpolation for half of the days causes some uncertainty in the satellite CMS. A spatial comparison can be made by looking at the number of melt days (NMD) for the RACMO2 results and the SSM/I data (Figures $3 \mathrm{~b}$ and 3c), averaged over the period 1979-2010. The general pattern of NMD is simulated well by RACMO2, with high values in the Peninsula and lower values around the coast of East Antarctica. There exist a few differences however; the coastal zone experiencing melt in East Antarctica is narrower in RACMO2, and the model also computes lower NMD in those areas. The northeasterly gradient in NMD on the Ross ice shelf is well captured, as well as areas with high NMD in Marie Byrd Land, and on both sides of the Peninsula. The model underestimation of NMD in coastal East Antarctica is offset by a higher NMD in the northern Peninsula. We speculate 


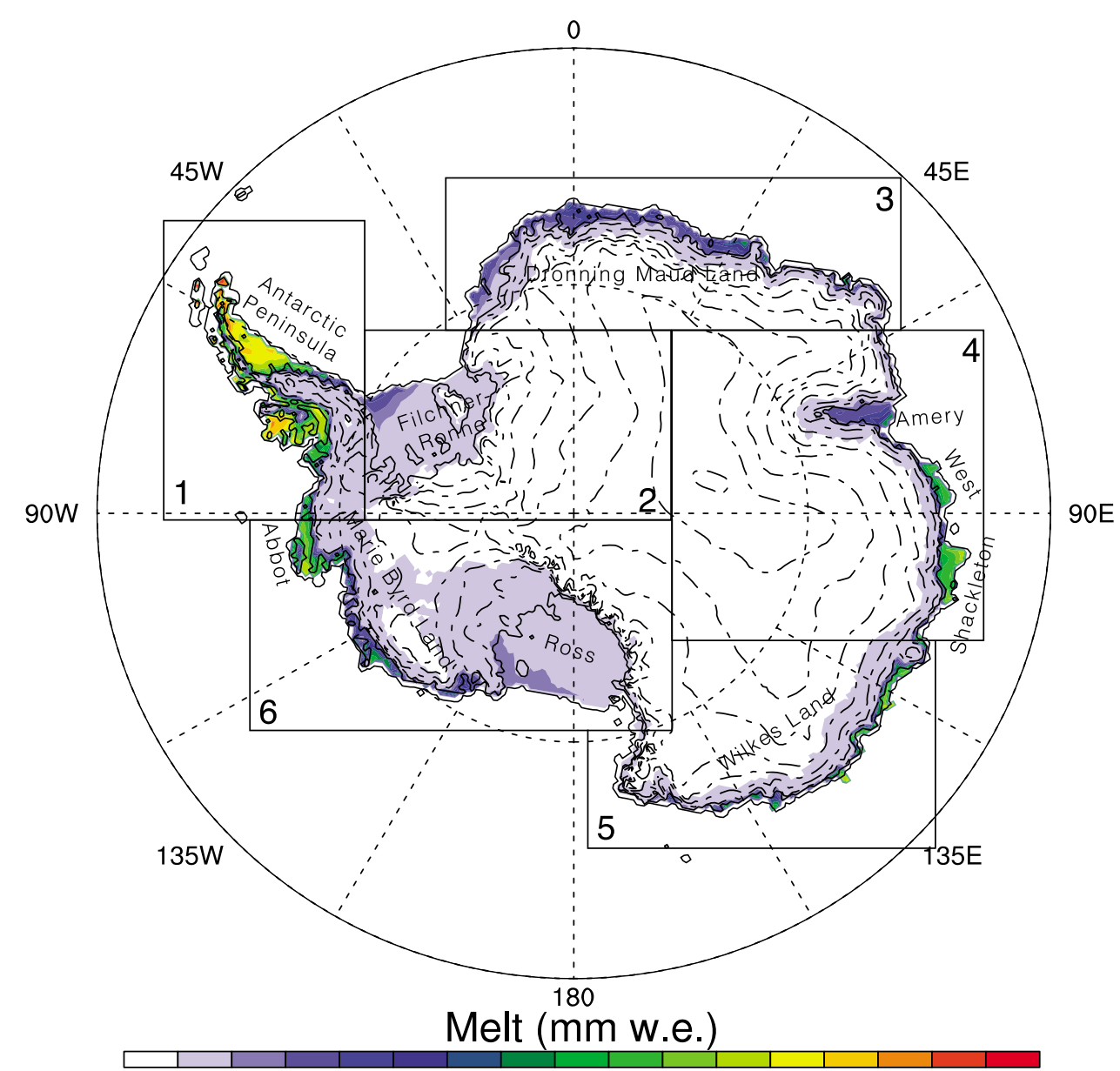

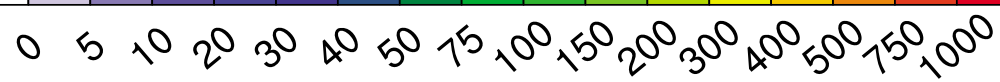

Figure 2. Mean snowmelt volume per unit area $\left(\mathrm{mm}\right.$ w.e. $\mathrm{y}^{-1}$ ) for the period 1979/80-2009/10. Black boxes indicate Antarctic regions following Zwally and Fiegles [1994] where 1 = Peninsula, $2=$ Filchner, 3 = Dronning Maud Land (DML), $4=$ Amery, $5=$ Wilkes, and $6=$ Ross.

however that this is an underestimation of satellite-detected melt resulting from the difficulty in sensing mountainous terrain interspersed with open water [Torinesi et al., 2003].

[6] In the auxiliary material (Figure S1), we show that satellite-derived CMS can be a good predictor of melt volume. The linear correlation between RACMO2 melt volume and satellite-observed CMS has a moderate $r^{2}=0.43$, but this includes the difference between RACMO2 and satellite CMS. The linear correlation between RACMO2 melt volume and RACMO2-derived CMS shows an $r^{2}=0.97$, with a slope of $4.84 \mathrm{Gt}^{-1}$ per one million $\mathrm{km}^{2} \mathrm{~d}$.

\section{Melt Volume Trends}

[7] None of the regions in Antarctica show a statistically significant trend in melt volume over the period 1979-2010. There is a large interannual variability — in many parts of Antarctica, the years between 1989-1992 show anomalously widespread melting [Picard et al., 2007; Tedesco et al., 2007; Ridley, 1993] whereas the austral summer 2008-2009 showed a 30-year minimum in snowmelt extent [Tedesco and Monaghan, 2009]. Limiting the time series to the period 1989-2010 leads to statistically significant, strongly negative trends in melt volume $\left(-4.1 \mathrm{Gt} \mathrm{y}^{-2}, p<0.01\right)$. The trend in satellite CMS (1979-2010) is negative and statistically significant $(p<0.01)$ at $-3.8 \cdot 10^{5} \mathrm{~km}^{2} \mathrm{~d} \mathrm{y}^{-1}$. However, this trend is influenced by a change in acquisition hours of different satellites. The RACMO2 CMS trend is also negative $\left(-2.8 \cdot 10^{5} \mathrm{~km}^{2} \mathrm{~d} \mathrm{y}^{-1}, p<0.1\right)$ when the modeled melt is synchronized with the satellite overpass times. When we base the CMS on 24 hours of RACMO2 data, the trend becomes smaller $\left(-1.5 \cdot 10^{5} \mathrm{~km}^{2} \mathrm{~d} \mathrm{y}^{-1}\right)$ and statistically insignificant. However, the trend in melt volume, which is the most relevant quantity, can be deduced

Table 1. Mean Melt Volume $\bar{V}$ and Standard Deviation $\sigma_{\bar{V}}$ for the Period 1979-2010 in Gt $\mathrm{y}^{-1}$ per Region as Shown in Figure 2

\begin{tabular}{llrr}
\hline & \multicolumn{1}{c}{ Region Name } & $\bar{V}$ & $\sigma_{\bar{V}}$ \\
\hline Region 1 & Peninsula & 59 & 23 \\
Region 2 & Filchner & 0.7 & 0.9 \\
Region 3 & Dronning Maud Land & 4.2 & 4.8 \\
Region 4 & Amery & 9.6 & 9.0 \\
Region 5 & Wilkes Land & 4.3 & 3.0 \\
Region 6 & Ross & 11.1 & 11.5 \\
Total & & 89 & 41 \\
\hline
\end{tabular}



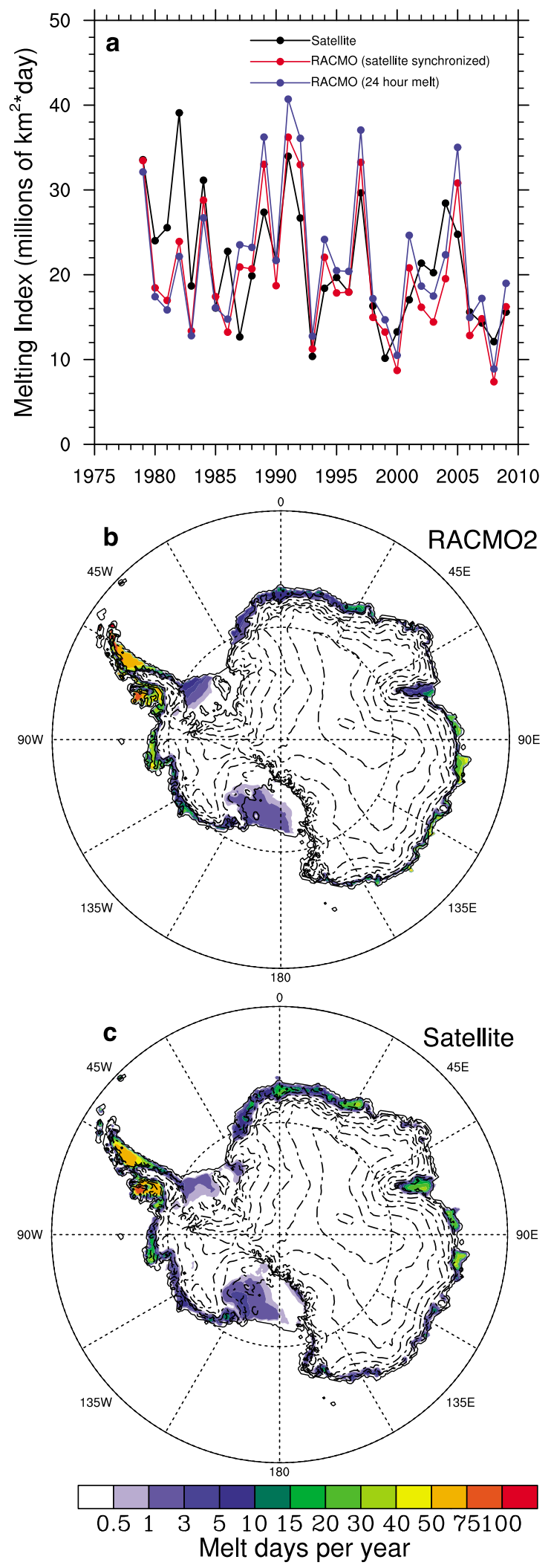

Figure 3. (a) Cumulative melting surface (CMS or melt index) in millions of $\mathrm{km}^{2} \mathrm{~d}$, for the period 1979/80-2009/ 10. Black $=\mathrm{SSM} / \mathrm{I}$ satellite data, red $=\mathrm{CMS}$ derived from satellite-synchronized RACMO2 output (see text), and blue = CMS from 24-hour RACMO2 output; (b) RACMO2 mean number of melt days per year (1979/80-2009/10); and (c) as in Figure $3 \mathrm{~b}$ for SSM/I and SMMR satellite data. only from RACMO2 data, and is slightly negative at $-0.90 \mathrm{Gt}^{-2}$ but not statistically significant.

\section{Discussion and Conclusions}

[8] The insignificant change in melt volume over the period 1979-2010 is not necessarily contradicted by the rapid regional warming observed from the 1950 s to the 2000 s in parts of the Antarctic Peninsula [Vaughan et al., 2003; Turner et al., 2005]. Of the four Antarctic Peninsula stations that have an air temperature record for 1979-2010 (READER database, http://www.antarctica.ac.uk/met/READER), only Faraday exhibits a statistically significant warming trend in summer temperature for that period. An observation-based reconstruction of DJF near-surface temperature [Monaghan et al., 2008] does show statistically significant trends in parts of West-Antarctica, although these are likely affected by recently discovered biases in the Byrd station temperature record (A. Monaghan, personal communication, 2011). A reconstruction of near-surface temperature without the questionable Byrd station (A. Monaghan, unpublished data, 2011) leaves DJF temperature trends for 1979-2010 insignificant over nearly the entire continent, and mostly suggests statistically insignificant cooling along the coastal margins. This finding also seems consistent with RACMO2 DJF nearsurface temperatures, which show no statistically significant trends for 1979-2010 in any of the areas that experience melt.

[9] The finding that snowmelt has not changed significantly over the past 31 years provides additional insight in the relation between snowmelt and the breakup of ice shelves in the past 20 years. Scambos et al. [2000] demonstrated that breakup of many ice shelves is preceded by intense ponding of meltwater at the surface. The circumstances needed for widespread ponding to occur have to be of an episodic nature: the flat trend in meltwater production precludes the option that the snowpack is being preconditioned by melt over multiple years prior to breakup. Rather, a single long and intense melt event, driven by a particular atmospheric circulation, likely precedes breakup of an ice shelf [Van den Broeke, 2005]. Still, ice-shelf breakup seems to have increased, and the ice shelves that break up had been in place for centuries [Scambos et al., 2000]. This suggests that an increased forcing must have been acting in recent decades, and that this forcing must come from below the ice shelf, in the form of increased basal melt [Shepherd et al., 2003]. A picture emerges in which the ultimate fate of ice shelves is governed by oceanic forcing from below, whereas the timing of their breakup depends on the occurrence of 'favorable' atmospheric conditions.

[10] Acknowledgments. Andrew Monaghan (National Center for Atmospheric Research, Boulder, CO, USA) is kindly thanked for discussing and analyzing surface temperature trends in correlation with meltwater volume. We would like to thank the anonymous reviewers for their help in improving this manuscript. ECMWF is thanked for providing access to their supercomputer facilities. This research was partly funded by NWO/ ALW grant 818.01.016, and partly supported by funding from the ice2sea programme from the European Union 7th Framework Programme, grant 226375. Ice2sea contribution 58 .

[11] The Editor thanks two anonymous reviewers for their assistance in evaluating this paper.

\section{References}

Ettema, J., M. R. van den Broeke, E. van Meijgaard, W. J. van de Berg, J. E. Box, and K. Steffen (2010), Climate of the Greenland ice sheet using a 
high-resolution climate model-Part 1: Evaluation, Cryosphere, 4, 511-527, doi:10.5194/tc-4-511-2010.

Fettweis, X., M. Tedesco, M. R. van den Broeke, and J. Ettema (2011), Melting trends over the Greenland ice sheet (1958-2009) from spaceborne microwave data and regional climate models, Cryosphere, 5, 359-375, doi:10.5194/tc-5-359-2011.

Helsen, M. M., M. R. van den Broeke, R. S. W. van de Wal, W. J. van de Berg, E. van Meijgaard, C. H. Davis, Y. Li, and I. Goodwin (2008), Elevation changes in Antarctica mainly determined by accumulation variability, Science, 320, 1626-1628, doi:10.1126/science.1153894.

Kuipers Munneke, P., M. R. van den Broeke, J. T. M. Lenaerts, M. G. Flanner, A. S. Gardner, and W. J. van de Berg (2011), A new albedo parameterization for use in climate models over the antarctic ice sheet, J. Geophys. Res., 116, D05114, doi:10.1029/2010JD015113.

Liu, H., L. Wang, and K. Jezek (2006), Spatiotemporal variations of snowmelt in Antarctica derived from satellite scanning multichannel microwave radiometer and Special Sensor Microwave Imager data (1978-2004), J. Geophys. Res., 111, F01003, doi:10.1029/2005JF000318.

Monaghan, A. J., D. H. Bromwich, W. Chapman, and J. C. Comiso (2008), Recent variability and trends of Antarctic near-surface temperature, J. Geophys. Res., 113, D04105, doi:10.1029/2007JD009094.

Picard, G., and M. Fily (2006), Surface melting observations in Antarctica by microwave radiometers: Correcting 26-year time series from changes in acquisition hours, Remote Sens. Environ., 104, 325-336.

Picard, G., M. Fily, and H. Gallée (2007), Surface melting derived from microwave radiometers: A climatic indicator in Antarctica, Ann. Glaciol. 46, 29-34.

Ridley, J. (1993), Surface melting on Antarctic Peninsula ice shelves detected by passive microwave sensors, Geophys. Res. Lett., 20(23), 2639-2642.

Scambos, T. A., C. Hulbe, M. Fahnestock, and J. Bohlander (2000), The link between climate warming and break-up of ice shelves in the Antarctic Peninsula, J. Glaciol., 46, 516-530.

Shepherd, A., D. Wingham, T. Payne, and P. Skvarça (2003), Larsen Ice Shelf has progressively thinned, Science, 302, 856-858, doi:10.1126/ science. 1089768 .
Tedesco, M. (2009), Assessment and development of snowmelt retrieval algorithms over Antarctica from K-band spaceborne brightness temperature (1979-2008), Remote Sens. Environ., 113, 979-997.

Tedesco, M., and A. J. Monaghan (2009), An updated Antarctic melt record through 2009 and its linkages to high-latitude and tropical climate variability, Geophys. Res. Lett., 36, L18502, doi:10.1029/2009GL039186.

Tedesco, M., W. Abdalati, and H. J. Zwally (2007), Persistent surface snowmelt over Antarctica (1987-2006) from 19.35 GHz brightness temperatures, Geophys. Res. Lett., 34, L18504, doi:10.1029/2007GL031199.

Torinesi, O., M. Fily, and C. Genthon (2003), Variability and trends of the summer melt period of Antarctic ice margin since 1980 from microwave sensors, J. Clim., 16, 1047-1060.

Turner, J., S. R. Colwell, G. J. Marshall, T. A. Lachlan-Cope, A. M. Carleton, P. D. Jones, V. Lagun, P. A. Reid, and S. Iagovkina (2005), Antarctic climate change during the last 50 years, Int. J. Climatol., 25, 279-294.

Van den Broeke, M. R. (2005), Strong surface melting preceded collapse of Antarctic Peninsula ice shelf, Geophys. Res. Lett., 32, L12815, doi:10.1029/2005GL023247.

Van den Broeke, M. R., G. König-Langlo, G. Picard, P. Kuipers Munneke, and J. Lenaerts (2010), Surface energy balance, melt and sublimation at Neumayer station (East Antarctica), Antarct. Sci., 22(1), 87-96, doi:10.1017/S0954102009990538.

Vaughan, D. G., G. J. Marshall, W. M. Connolley, C. L. Parkinson, R. Mulvaney, D. A. Hodgson, J. C. King, C. J. Pudsey, and J. Turner (2003), Recent rapid regional climate warming on the Antarctic Peninsula, Clim. Change, 60(3), 243-274.

Zwally, H. J., and S. Fiegles (1994), Extent and duration of Antarctic surface melting, J. Glaciol., 40(136), 463-476.

P. Kuipers Munneke, J. T. M. Lenaerts, and M. R. van den Broeke, Institute for Marine and Atmospheric Research, Utrecht University, PO Box 80005, Utrecht NL-3508 TA, Netherlands.

G. Picard, Laboratoire de Glaciologie et Géophysique de l'Environnement, CNRS/UJF, 54 rue Molière, St Martin d'Hères F-38402, France.

E. van Meijgaard, Royal Netherlands Meteorological Institute, PO Box 201 De Bilt NL-3730 AE, Netherlands. 